\title{
Aktionärinnen fordern Gleichberechtigung
}

Präsentation der djb-Studie 2010 am 1. Dezember 2010 in der Bertelsmann Repräsentanz, Berlin

Seit Jahrzehnten setzt sich der djb dafür ein, dass sich der Anteil von Frauen in Führungspositionen der Wirtschaft erhöht. Deutschland gehört zu den Schlusslichtern in der Europäischen Union im Hinblick auf Gender-Diversity in Vorstand, Aufsichtsrat und Führungspositionen in der Wirtschaft. Auf diesen Zustand aufmerksam zu machen war Anlass für die Aktion des djb „Aktionärinnen fordern Gleichberechtigung“ 2010.

Die Mitglieder des djb haben 2010 über 70 Hauptversammlungen großer deutscher börsennotierter Aktiengesellschaften besucht und dabei von ihrem Auskunftsrecht als Aktionärinnen Gebrauch gemacht. Die Auswertung der Befragung macht deutlich: Die Unternehmen bekennen sich zwar zu Diversity und verstehen darunter auch eine angemessene Beteiligung von Frauen. Aber Diversity wird in den Unternehmen nicht gelebt und umgesetzt. Am 1. Dezember 2010 wurde die Studie „Aktionärinnen fordern Gleichberechtigung “ mit den Projektergebnissen der Öffentlichkeit präsentiert. Hier abgedruckt sind das Grußwort von Liz Mohn (Geschäftsführerin der Bertelsmann Verwaltungsgesellschaft, Sprecherin der Familie Bertelsmann, Mitglied des Aufsichtsrates und des Personalausschusses der Bertelsmann AG, Stellv. Vorsitzende des Vorstandes und des Kuratoriums der Bertelsmann Stiftung) und die Rede von Prof. Dr. Marlene Schmidt (Vorsitzende der Kommission Arbeits-, Gleichstellungs- und Wirtschaftsrecht des djb, Rechtsanwältin in Frankfurt a.M., in der sie die Studie vorstellt ${ }^{1}$.

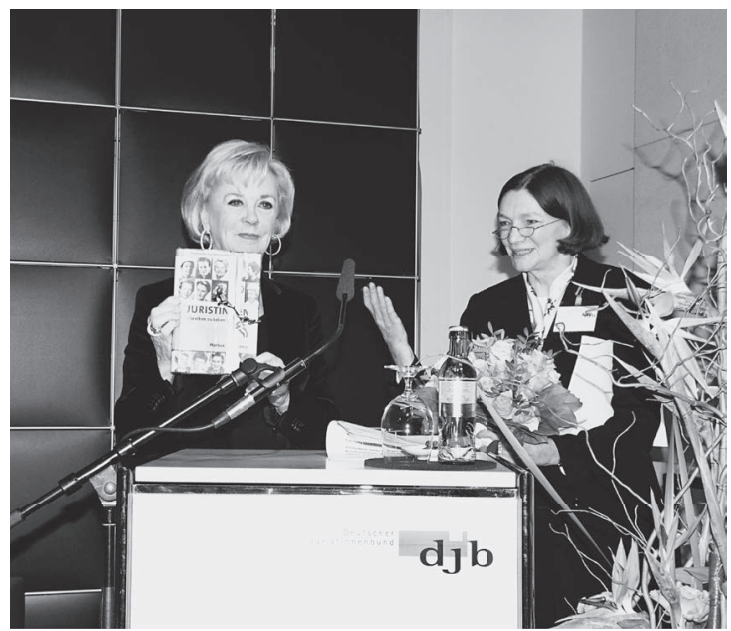

A Präsidentin Jutta Wagner überreicht Liz Mohn zum Dank ein Juristinnenlexikon.

Foto: @ Sharon Adler, Aviva-Berlin
Interessant ist, wenn Frauen in solche Gremien drängen, wird die Frage nach der Qualifikation gestellt. Dazu kann ich nur sagen, endlich wird die Frage mal gestellt.

Vera Gäde-Butzlaff

Anschließend diskutierten auf dem Podium:

n Vera Gäde-Butzlaff, Vorsitzende des Vorstands der Berliner Stadtreinigung, Berlin

- Thomas Fischer in Vertretung für Dr. Hermann Kues, Parlamentarischer Staatssekretär im Bundesministerium für Familie, Senioren, Frauen und Jugend, Berlin, der kurzfristig an der Teilnahme verhindert war

- Dr. Birgit Grundmann, Staatssekretärin des Bundesministeriums der Justiz, Berlin

- Sabine Kauper, Vorstand Finanzen, Phoenix Solar AG, München

- Prof. Dr. Klaus-Peter Müller, Vorsitzender der Regierungskommission Deutscher Corporate Governance Kodex, Vorsitzender des Aufsichtsrats der Commerzbank AG, Frankfurt am Main Die Diskussionsrunde wurde von Anke DomscheitBerg, European Women's Management Development Network, Berlin geleitet.

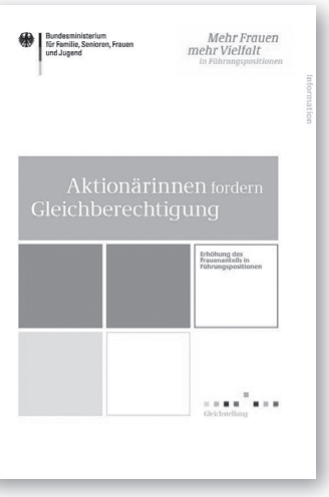

Die vom Bundesministerium für Familie, Senioren, Frauen und Jugend geförderte Aktion „Aktionärinnen fordern Gleichberechtigung. Erhöhung des Frauenanteils in Führungspositionen - insbesondere Aufsichtsratspositionen - deutscher Unternehmen" des Deutschen Juristinnenbundes ist Bestandteil des Stufenplanes Frauen in Führungspositionen. Die Dokumentation dieses Projektes gibt Handlungsempfehlungen und unterbreitet konkrete Vorschläge, wie ein Wandel hin zu einer angemessenen Beteiligung von Frauen im Management gelingen kann. http://www.bmfsfj.de/BMFSFJ/Service/

Publikationenpublikationsliste, did $=165456$.html.

1 Der von Prof. Dr. Marlene Schmidt vorbereitete Vortrag wurde von Präsidentin Jutta Wagner vorgetragen, da Prof. Dr. Schmidt wegen starker Schneefälle und daraus folgender Störungen des Flugverkehrs nicht rechtzeitig anreisen konnte. 